\title{
Laser Capture Microdissection and Colorectal Cancer Proteomics
}

\author{
Laura C. Lawrie and Stephanie Curran
}

\begin{abstract}
Summary
The ability to define protein profiles of normal and diseased cells is important in understanding cell function. Laser capture microdissection permits the isolation of specific cell types for subsequent molecular analysis. In this study we have established conditions for obtaining proteomic information from laser capture microdissected colorectal cancer cells. Laser capture microdissection was performed on toluidine blue-stained frozen sections of colorectal cancer. Proteins were solubilized from microdissected cells and the solubilized proteins were separated by two-dimensional gel electrophoresis: protein spots were characterized by peptide mass mapping using matrix assisted laser desorption ionization-time of flight mass spectrometry. Proteins isolated from laser capture microdissected tissue retained their expected electrophoretic mobility and peptide mass mapping was also unaffected. The ability to study the protein expression profile of specific cell types will allow for the identification of novel disease markers and therapeutic targets and also provide for the enhanced understanding of pathogenetic mechanisms.
\end{abstract}

Key Words: Colorectal cancer; 2-D gel electrophoresis; laser capture microdissection; mass spectrometry; proteomics.

\section{Introduction}

Interest in proteomics has increased steadily with the realization that characterization of DNA and RNA alone will not be sufficient to elucidate mechanisms of disease and to identify new drug targets and diagnostic markers (1). Proteomics includes the identification and characterization of proteins and the determination of post-translational modifications $(\mathbf{1 , 2})$. One of the primary applications of proteomics is to identify differentially expressed proteins by comparing the protein expression patterns between normal and diseased cells, such as tumor cells. Proteins that show enhanced expression in the diseased 
sample are potential diagnostic or prognostic markers or therapeutic targets. Proteomics encompasses a wide range of technologies, of which two-dimensional (2D) gel electrophoresis and mass spectrometry are currently the most widely used.

Molecular analysis of tumors requires the isolation of specific populations of cells since the presence of an admixture of cell types within a sample remains a major obstacle to meaningful biological analysis (3-5). Laser capture microdissection (LCM) permits the rapid and reliable procurement of a specific type of cell from a tissue section, in one step, under direct microscopic visualization (6-9). As part of our program of colorectal cancer research, we have developed a method to isolate colorectal cancer cells using LCM and combined this with proteomics analysis (10). We have shown that proteins solubilized from microdissected colorectal cancer cells can be separated by 2-D gel electrophoresis and that individual proteins can be identified by mass spectrometry (10). These findings provide the basis for the identification of novel markers of prognosis in colorectal cancer and enhanced understanding of the biology of colorectal cancer (11).

\section{Materials}

1. Toluidine blue.

2. Ethanol.

3. Xylene.

4. Coomassie Plus Protein Assay Reagent (Pierce).

5. Thiourea, (Amersham Biosciences).

6. Chaps [3-(3-cholamidopropyl)dimethylammonio-1-propanesulfonate] (Amersham Biosciences).

7. Mega 10 ( $N$-decanoyl- $N$-methylglucamine, Sigma).

8. OBG (1-O-Octyl- $\beta$-D-glucopyranoside, Aldrich).

9. Triton X-100 (polyoxyethylene- $p$-isooctylphenol, Amersham Biosciences).

10. Tris [Tris(hydroxymethyl)aminomethane] (Amersham Biosciences).

11. Dithiothreitol (DTT, Amersham Biosciences).

12. IPG 3-10 NL (immobilized $\mathrm{pH}$ gradient buffer, Amersham Biosciences).

13. $\beta$-Mercaptoethanol (Amersham Biosciences).

14. Tributylphosphine (Amersham Biosciences).

15. Immobiline Drystrips pI 3-10 NL (Amersham Biosciences).

16. Dry strip cover fluid (Amersham Biosciences).

17. Hydrochloric acid.

18. SDS (dodecyl sulfate, sodium salt).

19. Glycerol.

20. Iodoacetamide (Amersham Biosciences, UK).

21. NuPAGE, $7 \mathrm{~cm}, 4-12 \%, 1$ well, Bis-Tris gel (Invitrogen).

22. Low melting point agarose (Amersham Biosciences).

23. Colloidal blue staining kit ( Invitrogen). 
24. Methanol.

25. Acetic acid.

26. Porcine trypsin, sequencing grade (Promega).

27. $\alpha$-cyano-4-hydroxycinnamic acid (Aldrich).

28. Water, HPLC grade.

29. Preparation of Lysis Buffer

The protocol for the preparation of the protein lysis buffer was originally obtained from the National Cancer Institute protocols for the 2-D gel and mass spectrometric analysis of prostate tissue. We have used the same lysis buffer to successfully solubilize samples of colorectal tissue.

To prepare $50 \mathrm{~mL}$ of lysis buffer:

- Add 21 g urea to 35 mL HPLC-grade water in a 100-mL tube.

- Vortex until the urea has dissolved.

- Add sequentially:

a. $7.6 \mathrm{~g}$ of thiourea.

b. $2 \mathrm{~g}$ of CHAPS.

c. $0.5 \mathrm{~g}$ of Mega 10 .

d. $0.5 \mathrm{~g}$ of $\mathrm{OBG}$.

e. $250 \mu \mathrm{L}$ of Triton $\mathrm{X}-100$.

f. $0.25 \mathrm{~g}$ of Tris.

g. $0.4 \mathrm{~g}$ of DTT.

h. $500 \mu \mathrm{L}$ of IPG buffer pI 3-10NL.

i. $500 \mu \mathrm{L}$ of $\beta$-mercaptoethanol.

j. $10 \mu \mathrm{L}$ of tributylphosphine.

k. Trace of bromophenol blue.

- Make up volume to $50 \mathrm{~mL}$ with distilled water.

- Vortex until all components have dissolved.

- Store in 1-mL aliquots at $-20^{\circ} \mathrm{C}$.

30. Preparation of Equilibration Buffer

- Mix together $18 \mathrm{~g}$ urea and $10 \mathrm{~mL}$ of $0.5 \mathrm{M}$ Tris-HCl, pH 6.9.

- Vortex until dissolved.

- Add $10 \mathrm{~mL}$ of $20 \%$ SDS and $200 \mathrm{mg}$ of DTT.

- Invert gently to mix.

- Add $15 \mathrm{~mL}$ of glycerol.

- Vortex until thoroughly mixed.

- Add a trace of bromophenol blue as an indicator.

\section{Methods}

The methods described below outline (1) laser capture microdissection, (2) the solubilization of samples, (3) preparation of samples for 2-D gel electrophoresis, (4) separation and visualization of proteins by 2-D gel electrophoresis, (5) preparation of samples for mass spectrometry, and (6) identification of proteins by database searching. 


\subsection{Laser Capture Microdissection}

1. Frozen sections $(10 \mu \mathrm{m}$ in thickness) of either colorectal cancer or normal colorectal mucosa were cut on a cryostat (Leica, UK).

2. Four LCM sections were mounted onto clean uncoated glass microscope slides, air-dried for $5 \mathrm{~s}$, and then fixed at room temperature in $70 \%$ ethanol for $1 \mathrm{~min}$ (see Note 1). For comparison some sections were not subject to LCM and were placed directly in cold microfuge tubes (see step 7 below and Subheading 3.2.).

3. The fixed sections were then stained with toluidine blue (see Note 2). Staining with toluidine blue was carried out by covering the sections with $0.25 \%$ toluidine blue ( $\mathrm{pH} 4.5)$ for $5 \mathrm{~s}$ at room temperature and washing in $100 \%$ ethanol to remove excess dye; sections were then washed again in $100 \%$ ethanol and dehydrated in xylene.

4. Following complete evaporation of the xylene (see Note 3) the sections were microdissected using a PixCell II laser capture microdissection system (Arcturus Engineering, CA). The laser capture system was equipped with PixCell II image archiving software for Windows 95 (Arcturus Engineering).

5. The laser was operated with the following parameters: spot diameter $15 \mu \mathrm{m}$, pulse duration $50 \mathrm{~ms}$ and power $50 \mathrm{~mW}$ (see Note 4). Microdissected cells were obtained from 8-10 sections of each sample and a separate "cap" was used to capture cells from each section. Approximately 2500 laser pulses were used per cap (see Note 5).

6. Following microdissection the thermoplastic film containing the microdissected cells was separated from the rest of the cap, and all the films containing cells from one sample placed in a single $1.5-\mathrm{mL}$ microfuge tube and $125 \mu \mathrm{L}$ of protein lysis solution added (see Note 6 and Subheading 3.2.). These samples were then subject to 2-D gel electrophoresis (see Note 7 and Subheading 3.2.).

7. To determine the effects of histological processing and subsequent LCM on protein recovery, some frozen sections (whole tissue samples; see Subheading 3.2.2.) were placed directly into microcentrifuge tubes followed by the addition of protein lysis solution without the sections being subjected to either toluidine blue staining or LCM.

\subsection{Solubilization of Tissue Samples}

1. Use a Bradford protein assay kit (Pierce Coomassie Plus Protein Assay Reagent kit) to assess the amount of protein in each sample, with a view to adding around $500 \mu \mathrm{g}$ of protein to the gel.

2. For "whole" colon tissue samples we have found that solubilizing $3010-\mu \mathrm{m}$ frozen sections of normal tissue and $3010-\mu \mathrm{m}$ frozen sections of tumor tissue in $350 \mu \mathrm{L}$ and $500 \mu \mathrm{L}$ of lysis buffer respectively produced a final protein loading on the gel of approx $500 \mu \mathrm{g}$ for each type of sample.

After adding lysis buffer to the samples:

3. Vortex samples for $1 \mathrm{~min}$. 
4. Centrifuge samples at $14,000 \mathrm{~g}$ for $2 \mathrm{~min}$.

5. Crush remaining solid material with a pestle to aid solubilization.

6. Vortex for a further $1 \mathrm{~min}$.

7. Centrifuge at $14,000 \mathrm{~g}$ for a further $2 \mathrm{~min}$.

\subsection{Preparation of Samples for 2-D Gel Electrophoresis}

1. Add $125 \mu \mathrm{L}$ of normal sample (in duplicate) to IPGPhor strip holders.

2. Add $125 \mu \mathrm{L}$ of tumor sample (in duplicate) to IPGPhor strip holders.

3. Place IPG strips pI 3-10NL, gel side down, on top of sample.

4. Slowly add $800 \mu \mathrm{L}$ dry strip cover fluid to each strip holder to prevent strips from drying out.

5. Allow strips to absorb protein solution overnight.

6. Remove strips from strip holders.

7. Clean strip holders.

8. Cover electrodes of strip holders with slightly damp electrode strips (approx 4 $\mathrm{mm} \times 4 \mathrm{~mm}$ ), to help soak up excess salt during first dimension run.

9. Return rehydrated strips to strip holders, gel side down.

10. Add $800 \mu \mathrm{L}$ dry strip cover fluid to each strip holder.

\subsection{Isoelectric Focusing}

An IPGphor system (Amersham Biosciences) was used to separate the proteins in the first dimension according to their isoelectric point (pI), under the following conditions:

1. $30 \mathrm{~min}$ at $20 \mathrm{~V}$.

2. $90 \mathrm{~min}$ at $200 \mathrm{~V}$.

3. $90 \mathrm{~min}$ gradient to $3500 \mathrm{~V}$.

4. $35 \mathrm{~h}$ at $3500 \mathrm{~V}$.

On completion of focusing the strips were equilibrated in $5 \mathrm{~mL}$ of equilibration buffer for $30 \mathrm{~min}$. Strips were equilibrated for a further $30 \mathrm{~min}$ in the above equilibration buffer, but this time DTT was replaced with $500 \mathrm{mg}$ iodoacetamide.

\subsection{SDS-PAGE Separation}

1. Proteins were separated in the second dimension according to their molecular weight on a 7-cm NuPAGE 4-12\%, 1 well, Bis-Tris gel (Invitrogen).

2. The IPG strips were attached to the second dimension gel with a $4 \%$ low melting point agarose solution (Amersham Biosciences, UK). Normal and tumor samples from the same patient were run in the same gel tank to eliminate any differences in protein mobility that could be caused by variation in the gel electrophoresis.

3. Gels were run at a constant $120 \mathrm{~V}$ until the bromophenol dye front reached the end of the gel. 


\subsection{Visualization of Proteins}

1. Proteins were visualized using a colloidal blue staining kit (Invitrogen). Gels were initially fixed in a solution containing methanol (50\% v/v), acetic acid (10\% $\mathrm{v} / \mathrm{v})$ for $30 \mathrm{~min}$, then transferred to a staining solution containing methanol (20\% $\mathrm{v} / \mathrm{v})$, stainer A $(20 \% \mathrm{v} / \mathrm{v})$, stainer B (5\% v/v) for overnight staining to visualize the proteins.

2. Gels were destained using HPLC-grade water with microwave heating $(5 \times 1 \mathrm{~min}$ on full power, replacing the water each time) to facilitate the destaining process.

\subsection{Detection of Differential Protein Expression}

1. Destained gels were immediately photographed to produce a black-and-white image.

2. Gel photographs were scanned on a flatbed scanner to produce a computer image, which was then enlarged and printed onto sheets of acetate. Overlaying the normal and tumor acetate gel pictures allowed proteins that were differentially expressed to be rapidly detected by visual inspection.

3. Differentially expressed protein spots were cut from the individual gels in preparation for identification by mass spectrometry.

\subsection{Identification of Proteins From Gels}

1. Individual proteins were identified by peptide mass mapping (12-14).

2. Protein spots were cut from the gel, washed to remove Coomassie stain, reduced with DTT, and alkylated with iodoactetamide, then digested with trypsin (see Note 8).

3. The resultant tryptic peptides were extracted from the gel pieces under full automation (Pro-Gest Robot, Genomic Solutions).

4. The tryptic fragments were desalted using micro-porous tips (Millipore), and deposited onto a sample plate along with a matrix chemical ( $\alpha$-cyano-4hydroxycinnamic acid) under full automation (Pro-MS, Genomic Solutions).

5. The masses of the tryptic fragments were then determined by matrix-assisted laser desorption ionization time-of-flight mass spectrometry (MALDI-TOF MS) (see Note 9).

\subsection{Protein Identification Through Database Searching}

1. To identify the original protein, the masses of the tryptic peptides were entered into a protein database-searching program. Database-searching programs attempt to match the experimentally obtained masses of tryptic peptides with the theoretically calculated masses of tryptic peptides derived from all proteins within a database.

2. We used the MS-Fit database-searching program (http://prospector. ucsf.edu/ ucsfhtml4.0/msfit.htm) to identify differentially expressed proteins.

3. The results from a database search consist of a list of protein "hits," ranked according to a statistical scoring system that takes into account how many pep- 
tides have been matched to the protein in the database and the accuracy of these matches. The database search was restricted to search only for human proteins; no restriction was placed on either the molecular weight or the isoelectric point of the protein.

4. To be confident that the correct protein was identified, a clear difference in statistical score between the proteins ranked first and second in the results list should be obtained. It is also important to check that the major tryptic peptides from the mass spectrum are assigned to the matching peptides in the database.

\section{Notes}

1. It is important to use uncoated microscope slides, as any coating of the slides with adhesive, e.g., poly-L-lysine or aminopropylethoxy silane-coated slides, will prevent the successful transfer of microdissected cells.

2. A rapid single-step histological staining method was selected to minimize or avoid any loss of or alterations to cellular proteins during the staining procedure.

3. It is crucial to the success of laser capture microdissection that the stained sections are completely dehydrated prior to attempting microdissection. Incompletely dehydrated sections will not be successfully microdissected. We have found that even a trace of moisture will inhibit successful transfer of microdissected cells.

4. The optimum setting for the laser, i.e., the settings that ensure transfer (pick-up) of selected cells, has to be determined experimentally for each type of tissue and in our experience often varies on a day-to-day to basis. The values that we have quoted are the ones that we have generally found to be useful. Occasionally we have found that it is not possible to microdissect an individual section even when the section has been completely dehydrated, as the cells remain adherent to the slide. The reasons for this are obscure and we are aware that other users have also made the same observation.

5. The number of laser pulses required to obtain sufficient numbers of cells for proteomics is considerably higher than the number of cells required for most nucleic acid-based molecular analyses. There is no protein equivalent of the polymerase chain reaction to permit target amplification.

6. This modification of the manufacturer's recommended protocol for processing the caps ensured that small volumes of protein lysis solution could be used to obtain a sufficiently concentrated protein solution suitable for subsequent $2 \mathrm{D}$ gel electrophoresis.

7. The solubilized LCM samples were analyzed directly by $2 \mathrm{D}$ gel electrophoresis with the entire volume of protein lysis solution applied to a single IPG strip.

8. Trypsin cleaves proteins (at peptide bonds) after arginine and lysine residues. This action produced a set of tryptic fragments unique to each protein.

9. In MALDI-TOF MS the tryptic fragments are mixed with $\alpha$-cyano-4hydroxycinnamic acid and deposited on a sample plate. An ultraviolet laser is fired at the mixture, which causes the peptides to be desorbed from the sample plate and ionized. A high-voltage gradient is then applied, which causes the ion- 
ized peptides to be accelerated into a flight tube. The ions separate in the flight tube according to their mass-to-charge ratio, with lighter ions arriving at the detector before heavier ions of the same charge. The time the ions take to reach the detector (time of flight), compared with standard proteins of known mass, is used to calculate the masses of the tryptic peptides.

\section{Acknowledgments}

LCL was the Jean V. Baxter Fellow of the Scottish Hospital Endowments Research Trust. The Aberdeen Colorectal Cancer Research Initiative is supported by a grant from The University of Aberdeen Development Trust.

\section{References}

1 Lawrie, L. C., Fothergill, J. E., and Murray G.I. (2001) Spot the differences: Proteomics in cancer research. Lancet Oncol. 2, 270-277.

2 Lawrie, L. C. and Murray, G. I. (2002) The proteomics of colorectal cancer. Applied Genom. Proteom. 1, 169-181.

3 Zou, T. T., Selaru, F. M., Xu, Y., Shustova, V., Yin, J., Mori, Y., et al. (2002) Application of cDNA microarrays to generate a molecular taxonomy capable of distinguishing between colon cancer and normal colon. Oncogene 21, 4855-4862.

4 Sugiyama, Y., Sugiyama, K., Hirai, Y., Akiyama, F., and Hasumi, K. (2002) Microdissection is essential for gene expression profiling of clinically resected cancer tissues. Am. J. Clin. Pathol. 117, 109-116.

5 Notterman, D. A., Alon, U., Sierk, A. J., and Levine, A. J. (2001) Transcriptional gene expression profiles of colorectal adenoma, adenocarcinoma and normal tissue examined by oligonucleotide arrays. Cancer Res. 61, 3124-3130.

6 Curran, S., McKay, J. A., McLeod, H. L., and Murray, G. I. (2000) Laser capture microscopy. J. Clin. Pathol. Mol. Pathol. 53, 64-68.

7 Curran, S. and Murray G. I. (2002) Tissue microdissection and its applications in pathology. Curr. Diagnos. Pathol. 8, 183-192.

8. Dundas, S. R., Curran, S., and Murray, G. I. (2002) Laser capture microscopy: application to urological cancer research. UroOncology 2, 33-35.

9 Craven, R. A., Totty, N., Harnden, P., Selby, P. J., and Banks, R. E. (2002) Laser capture microdissection and two-dimensional polyacrylamide gel electrophoresis: evaluation of tissue preparation and sample limitations. Am. J. Pathol. 160, 815-822.

10 Lawrie, L., Curran, S., McLeod, H. L., Fothergill, J. E., and Murray, G. I. (2001) Application of laser capture microdissection and proteomics in colon cancer. J. Clin. Pathol: Mol. Pathol. 54, 253-258.

11 McLeod, H. L. and Murray, G. I. (1999) Tumour markers of prognosis in colorectal cancer. Brit. J. Cancer 79, 191-203.

12 Wilm, M., Shevchenko, A., Houthaeve, T., Breit, S., Schweigerer, L., Fotsis, T., and Mann, M. (1996) Femtomole sequencing of proteins from polyacrylamide gels by nano-electrospray mass spectrometry. Nature 379, 466-469. 
13. Shevchenko, A., Wilm, M., Vorm, O., and Mann, M. (1996) Mass spectrometric sequencing of proteins from silver stained polyacrylamide gels. Anal. Chem. 68, $850-858$.

14. Ritchie, H., Lawrie, L. C., Crombie, P. W., Mosesson, M. W. and Booth, N. A. (2000) Cross-linking of plasminogen activator 2 and $\alpha 2$-antiplasmin to fibrino(gen). J. Biol. Chem. 275, 24,915-24,920. 